\title{
Patient safety culture in Peking University Cancer Hospital in China: baseline assessment and comparative analysis for quality improvement
}

\author{
Xiyao Zhong ${ }^{1}$, Yuqin Song ${ }^{1}$, Christine Dennis², Donna J. Slovensky ${ }^{3}$, Lim Yee Wei ${ }^{4}$, Jie Chen ${ }^{5}$ and Jiafu Ji ${ }^{* *}$
}

\begin{abstract}
Background: Limited information is available regarding the patient safety culture in Chinese hospitals. This study aims to assess the patient safety culture in Peking University Cancer Hospital and to identify opportunities for improving the organization's safety culture.

Methods: A cross-sectional study was conducted in April 2018 and 2019, respectively. Data on patient safety culture were collected from clinical and administrative staffs using the Hospital Survey on Patient Safety Culture (HSOPSC).

Results: Twelve composite dimension variables were hierarchically clustered. Three highest positive response dimensions include 'Organizational Learning and continuous improvement' (92.9\%), Teamwork within units' (89.7\%), and 'Hospital management support for patient safety' (83.7\%), while 3 lowest positive response dimensions included 'Frequency of events reported' (43.9\%), 'Non-punitive response to error' (51.1\%), 'Communication openness' (52.2\%), and 'Staffing' (53.7\%).

Compared to the average scores of the United States, the scores of the Peking University Cancer Hospital was significantly lower on 'Communication openness' and 'Frequency of events reported'. After targeted continuous improvement based on results in 2018, all 12 dimensions surprisingly increased in the safety culture conducted in 2019.

Conclusion: Inadequate feedback and communications about error and lack of communication openness are key challenges for patient safety in the delivery of care in this hospital. Results of this baseline survey indicate the need for a modified approach and attention to context when designing interventions aimed at improving the safety culture in this organization.
\end{abstract}

Keywords: Patient safety, Hospital survey on patient safety culture (HSOPSC), Chinese hospitals

\section{Background}

Patient safety is receiving growing attention in China. Developing and maintaining a positive patient safety culture among clinical and administrative staff is widely recognized as a crucial element in the improvement of patient safety in healthcare organizations. A culture of safety has been defined as "a collaborative environment in which

\footnotetext{
* Correspondence: jijiafu@hsc.pku.edu.cn

Written on behalf of AME Healthcare Research and Quality Cooperative Group

${ }^{1}$ Key Laboratory of Carcinogenesis and Translational Research (Ministry of Education/Beijing), Peking University Cancer Hospital and Institute, Beijing 100142, China

Full list of author information is available at the end of the article
}

skilled clinicians treat each other with respect, leaders drive effective teamwork and promote psychological safety, teams learn from errors and near misses, caregivers are aware of the inherent limitations of human performance in complex systems (stress recognition), and there is a visible process of learning and driving improvement through debriefings" [1]. Simply put, safety culture refers to the beliefs, values, perceptions and attitudes of patient safety shared among members of the organization. It is recognized as a key element in improving quality of care, and in decreasing/preventing medical errors. Assessment of the safety culture helps leaders in healthcare organizations to determine areas for patient safety improvement,

(c) The Author(s). 2019 Open Access This article is distributed under the terms of the Creative Commons Attribution 4.0 International License (http://creativecommons.org/licenses/by/4.0/), which permits unrestricted use, distribution, and reproduction in any medium, provided you give appropriate credit to the original author(s) and the source, provide a link to the Creative Commons license, and indicate if changes were made. The Creative Commons Public Domain Dedication waiver (http://creativecommons.org/publicdomain/zero/1.0/) applies to the data made available in this article, unless otherwise stated. 
to evaluate the success of patient safety interventions, to benchmark against other organizations, and to meet regulatory requirements.

The Agency for Healthcare Research and Quality (AHRQ) is a unit within the U.S. Department of Health and Human Services dedicated to "producing evidence to make health care safer, higher quality, more accessible, equitable, and affordable" [2]. In support of this mission, AHRQ developed a tool to assess healthcare organizational culture regarding patient safety. The Hospital Survey on Patient Safety Culture (HSOPSC) was released in 2004 and has been widely used by healthcare organizations in the U.S. and internationally [3]. The HSOPSC measures an organization's safety culture based on 42 items that measure 12 composites (10 safety dimensions and 2 outcome dimensions), staff perceptions on patient safety issues, and adverse events reporting. The English language version of the survey is available from the AHRQ.gov website [2].

In this study, a Chinese-translated version of the HSOPSC tool was used to conduct a baseline assessment and comparative analysis of the patient safety culture in Peking University Cancer Hospital (PUCH) to identify opportunities for improvement in the organization's safety culture.

The Peking University Cancer Hospital, one of the most comprehensive cancer centers in China, has a total capacity of 790 beds with all major medical specialties and services represented. The hospital, located in the capital city of Beijing, is an academic medical center with a strong basic and clinical research focus in addition to providing cancer treatments using a wide variety of interventional approaches.

\section{Methods}

\section{Participants and assessment tool}

The HSOPSC provides a comprehensive assessment of patient safety culture. The guideline is comprised of 42 items that measure 12 composites (10 safety dimensions and 2 outcome dimensions).

The investigation instrument was a validated Chinese version of the HSOPSC [4]. It has also been used in many Chinese studies [5, 6]. The translated HSOPSC was delivered as an anonymous online survey, during April 2018 and 2019, respectively, to all the clinical and non-clinical hospital staff members whose jobs contributed to patient safety. Specifically, these respondents, included physicians, nurses, clinical and non-clinical staff, pharmacy and laboratory staff, dietary and radiology staff, supervisors, and hospital managers. The defined study sample comprised 1931 individuals.

\section{Statistical analysis}

Data were analyzed using SPSS 20.0. Univariate analysis was conducted to summarize the demographic characteristics of respondents. Respondents' gender, job category, work unit, experience (in current hospital, department, and work area), and weekly hours of work were presented.

The HSOPSC is comprised of 42 items that measure 12 composites (i.e. each composite was calculated based on responses to 3-4 items). Items were scored on a fivepoint frequency scale and included both positively and negatively worded items. For each positively worded item, the percentage of positive responses was calculated, i.e., the percentage of respondents answering the question as "Strongly Agree/Agree" or "Always/Most of the time".

Similarly, for reverse worded items, disagreement indicates a positive response, so the responses 'Strongly Disagree/Disagree' or 'Never/Rarely' are considered positive.

Composite level scores were computed by summing the items within the composite scales and dividing by the number of items with non-missing values. Cronbach's Alpha was used to test for the internal consistency and reliability of the 12 composites.

The Pearson's correlation coefficient was used to examine the association between frequency of events reported and overall perception of safety and the remaining 10 composites at the bivariate level. The 'number of events reported' question asks for the number of adverse events reports the individual had submitted in the previous 12 months.

We used generalised estimating equations with an independence working correlation to fit a proportional odds logistic regression model for number of events and patient safety grade. The two outcomes were grouped into 3 categories: 'Poor of Failing', 'Acceptable', and 'Excellent/Good' for patient safety, and '> 5', ' $1-5$ ', and 'no events' for number of events.

Finally, the percent positive responses for each composite variable calculated for Peking University Cancer Hospital, and published data from the Kingdom of Saudi Arabia, Lebanon, Turkey and the United States were compared collectively. A one-sample t-tests was used to compare the results of Peking University Cancer Hospital against these other countries in pairs.

\section{Results}

\section{Respondents' characteristics}

A total of 1562 of the 1931 questionnaires was returned for a response rate of $80.9 \%$. Respondents' characteristics are presented in Table 1. The majority of respondents were female $(72.7 \%)$. Almost one-third of respondents worked in surgical units (29.3\%), while $20.5 \%$ worked in medical units, $27.3 \%$ in diagnostic units, $14.3 \%$ in administration, and $8.7 \%$ in other units. Doctors comprised $22.1 \%$ of the sampled respondents, $38.8 \%$ were nurses, 
Table 1 Characteristics of respondents of the Hospital Survey on Patient Safety Culture (HSOPSC) conducted at the Peking University Cancer Hospital

\begin{tabular}{|c|c|c|c|c|c|}
\hline & & & & & \\
\hline Characteristics & $\mathrm{N}$ & $\%$ & Characteristics & $\mathrm{N}$ & $\%$ \\
\hline Gender & & & $60-79 h$ & 182 & 11.7 \\
\hline Male & 426 & 27.3 & $80-99 h$ & 29 & 1.9 \\
\hline Female & 1136 & 72.7 & $100 \mathrm{~h}$ & 21 & 1.3 \\
\hline Job category & & & Job involves direct contact with patients & & \\
\hline Doctor & 345 & 22.1 & Yes & 1135 & 72.7 \\
\hline Nurse & 606 & 38.8 & No & 427 & 27.3 \\
\hline Technician & 398 & 25.5 & Patient safety grade & & \\
\hline Administration & 213 & 13.6 & Excellent & 540 & 34.6 \\
\hline Work unit & & & Good & 761 & 48.7 \\
\hline Administration & 223 & 14.3 & Acceptable & 231 & 14.8 \\
\hline Diagnostics & 426 & 27.3 & Poor & 25 & 1.6 \\
\hline ICU, operating room, anesthesiology & 136 & 8.7 & Failing & 5 & 0.3 \\
\hline Medical & 320 & 20.5 & Number of adverse events reported & & \\
\hline Surgical & 457 & 29.3 & No events & 945 & 60.5 \\
\hline Clinical department or not & & & 1 to 2 event reports & 453 & 29.0 \\
\hline Yes & 994 & 63.6 & 3 to 5 event reports & 104 & 6.7 \\
\hline No & 568 & 36.4 & 6 to 10 event reports & 34 & 2.2 \\
\hline Experience in current hospital (years) & & & 11 to 20 event reports & 16 & 1.0 \\
\hline Less than 1 & 94 & 6.0 & 21 event reports or more & 10 & 0.6 \\
\hline 1 to 5 & 507 & 32.5 & & & \\
\hline
\end{tabular}

6 to 10

11 to 15

16 to 20

21 years or more

Experience in current department (years)

Less than 1

1 to 5

6 to 10

11 to 15

16 to 20

21 years or more

Experience in current work area (years)

Less than 1

1 to 5

6 to 10

11 to 15

16 to 20

21 years or more

Hours of work per week

$$
\begin{aligned}
& <20 \mathrm{~h} \\
& 20-39 \mathrm{~h}
\end{aligned}
$$$$
8
$$

40-59h
Table 1 Characteristics of respondents of the Hospital Survey on Patient Safety Culture (HSOPSC) conducted at the Peking University Cancer Hospital (Continued)

$25.5 \%$ were technicians, and $13.6 \%$ were administrative staff. A third of respondents had between 1 and 5 years of experience (32.5\%), while $23.1 \%$ had between 6 and 10 years of experience. Almost three-quarters of respondents indicated that their work required direct contact with patients $(72.7 \%)$.

Approximately half of respondents gave the hospital a 'Good' patient safety grade (48.7\%). 60.5\% of the sampled respondents reported no adverse safety events, approximately a third (29\%) reported 1 to 2 events, and $6.7 \%$ reported 3 to 5 events. It is notable that only $1.6 \%$ of respondents reported 11 or more events although this still equates to several hundred reported events.

\section{Patient safety culture composite scores}

The twelve composite variable scores were hierarchically clustered. Cluster I (highest positive response) grouped 'Learning and continuous improvement' (92.9\%), 'Teamwork within units' (89.7\%), and 'Hospital management support for patient safety' (83.7\%). Cluster II (lowest positive response) included 'Frequency of events reported' (43.9\%), 'Non-punitive response to error' (51.1\%), 'Communication openness' (52.2\%), and 'Staffing' (53.7\%).

Results reported in Table 2 indicate that internal consistency and reliability of the 12 composites were acceptable, with Cronbach's values ranging from a low of 
Table 2 Distribution of positive responses and scores for survey composites and items

\begin{tabular}{|c|c|c|c|}
\hline Composites and survey items & $\begin{array}{l}\text { Average positive } \\
\text { response }(\%)^{*}\end{array}$ & Mean & SD \\
\hline Overall perception of safety (Cronbach's a $=0.61)$ & 74.6 & 4.0 & 0.7 \\
\hline Patient safety is never sacrificed to get more work done & 85.5 & 4.2 & 1.0 \\
\hline Our policies and procedures and systems are effective in preventing errors & 77.4 & 4.0 & 0.9 \\
\hline It is just by chance that more serious mistakes do not happen around here $(R)^{* *}$ & 71.4 & 4.0 & 1.0 \\
\hline We have patient safety problems in this unit( $R)$ & 64.0 & 3.8 & 1.0 \\
\hline Supervisor/Manager expectations \& actions promoting patient safety (Cronbach's a $=0.78$ ) & 81.6 & 4.1 & 0.6 \\
\hline $\begin{array}{l}\text { My supervisor/manager says a good word when he/she sees a job done according to established } \\
\text { patient safety procedures }\end{array}$ & 79.2 & 4.0 & 0.8 \\
\hline My supervisor/manager seriously considers staff suggestions for improving patient safety & 89.1 & 4.3 & 0.7 \\
\hline $\begin{array}{l}\text { Whenever pressure builds up, my supervisor/manager wants us to work faster, even if it means } \\
\text { taking shortcuts(R) }\end{array}$ & 72.3 & 3.9 & 1.0 \\
\hline My supervisor/manager overlooks patient safety problems that happen over and over(R) & 85.7 & 4.2 & 0.8 \\
\hline Organizational learning and continuous improvement (Cronbach's a =0.79) & 92.9 & 4.4 & 0.6 \\
\hline We are actively doing things to improve patient safety & 96.4 & 4.5 & 0.6 \\
\hline Mistakes have led to positive changes here & 95.1 & 4.4 & 0.7 \\
\hline After we make changes to improve patient safety, we evaluate their effectiveness & 87.3 & 4.2 & 0.7 \\
\hline Teamwork within units (Cronbach's a = 0.87) & 89.7 & 4.3 & 0.7 \\
\hline Staff supports one another in this unit & 92.8 & 4.4 & 0.8 \\
\hline When a lot of work needs to be done quickly, we work together as a team to get the work done & 92.8 & 4.4 & 0.7 \\
\hline In this unit, people treat each other with respect & 91.6 & 4.4 & 0.8 \\
\hline When members of this unit get really busy, other members of the same unit help out & 81.6 & 4.1 & 0.9 \\
\hline Staffing (Cronbach's a = 0.53) & 53.7 & 3.5 & 0.7 \\
\hline We have enough staff to handle the workload & 75.9 & 4.0 & 1.0 \\
\hline Staff in this unit work longer hours than is best for patient care (R) & 39.7 & 3.1 & 1.2 \\
\hline We use more agency/temporary staff than is best for patient care (R) & 65.9 & 3.8 & 1.0 \\
\hline When the work is in "crisis mode" we try to do too much, too quickly (R) & 33.4 & 3.0 & 1.2 \\
\hline Hospital management support for patient safety (Cronbach's a = 0.74) & 83.7 & 4.2 & 0.7 \\
\hline Hospital management provides a work climate that promotes patient safety & 80.8 & 4.1 & 0.8 \\
\hline The actions of hospital management show that patient safety is a top priority & 90.7 & 4.3 & 0.7 \\
\hline Hospital management seems interested in patient safety only after an adverse event happens (R) & 75.9 & 4.0 & 0.9 \\
\hline Hospital handoffs \& transitions (Cronbach's a = 0.86) & 73.1 & 4.0 & 0.7 \\
\hline $\begin{array}{l}\text { Things "fall between the cracks", i.e., things might go uncontrolled and get lost when transferring } \\
\text { patients from one unit to another (R) }\end{array}$ & 55.1 & 3.6 & 0.9 \\
\hline Important patient care information is often lost during shift changes (R) & 87.2 & 4.3 & 0.8 \\
\hline Problems often occur in the exchange of information across hospital units (R) & 75.4 & 4.0 & 0.8 \\
\hline Shift changes are problematic for patients in this hospital (R) & 74.6 & 4.0 & 0.9 \\
\hline Communication openness (Cronbach's a $=0.57$ ) & 52.2 & 3.5 & 0.7 \\
\hline Staff will freely speak up if they see something that may negatively affect patient care & 70.0 & 3.9 & 0.9 \\
\hline Staff feel free to question the decisions or actions of those with more authority & 21.3 & 2.9 & 1.0 \\
\hline Staff are afraid to ask questions when something does not feel right (R) & 65.3 & 3.8 & 1.0 \\
\hline Feedback and communications about error (Cronbach's a =0.76) & 77.6 & 4.1 & 0.7 \\
\hline We are given feedback about changes put into place based on event reports & 76.8 & 4.1 & 0.8 \\
\hline We are informed about errors that happen in this unit & 73.9 & 4.1 & 0.9 \\
\hline In this unit, we discuss ways to prevent errors from happening again & 82.1 & 4.2 & 0.8 \\
\hline
\end{tabular}


Table 2 Distribution of positive responses and scores for survey composites and items (Continued)

\begin{tabular}{|c|c|c|c|}
\hline Composites and survey items & $\begin{array}{l}\text { Average positive } \\
\text { response (\%) }\end{array}$ & Mean & SD \\
\hline Frequency of events reported (Cronbach's a $=0.89$ ) & 43.9 & 3.3 & 1.0 \\
\hline When a mistake is made, but is caught and corrected affecting the patient, how often is this reported? & 44.0 & 3.4 & 1.1 \\
\hline When a mistake is made, but has no potential to harm the patient, how often is this reported? & 41.5 & 3.3 & 1.1 \\
\hline When a mistake is made that could harm the patient, but does not, how often is this reported? & 46.2 & 3.4 & 1.2 \\
\hline Non-punitive response to error (Cronbach's a $=0.68$ ) & 51.1 & 3.4 & 0.8 \\
\hline Staff feel like their mistakes are held against them (R) & 45.7 & 3.2 & 1.1 \\
\hline When an event is reported, it feels like the person is being written up, not the problem ( $R$ ) & 75.0 & 3.9 & 1.0 \\
\hline Staff worry that mistakes they make are kept in their personnel file (R) & 35.5 & 3.0 & 1.1 \\
\hline Teamwork across hospital units (Cronbach's a $=0.84$ ) & 76.2 & 4.0 & 0.7 \\
\hline Hospital units do not coordinate well with each other and this might affect patient care (R) & 65.7 & 3.8 & 1.0 \\
\hline There is good cooperation among hospital units that need to work together & 79.1 & 4.0 & 0.8 \\
\hline It is often not easy to work with staff from other hospital units (R) & 75.0 & 3.9 & 0.9 \\
\hline Hospital units work well together to provide the best care for patients & 85.2 & 4.2 & 0.8 \\
\hline
\end{tabular}

*The composite-level percentage of positive responses was calculated using the following formula: (number of positive responses to the items in the composite/ total number of responses compared with the items (positive, neutral, and negative) in the composite (excluding missing responses) $)^{*} 100$

**(R) Negatively worded items that were reverse coded

0.53 (Staffing) to a high of 0.87 (Teamwork within units). According to the HSOPSC user's guide [7], a Cronbach's $\alpha 0.6$ is acceptable, whereas Bowling [8] states that a value of 0.5 or above indicates good internal consistency. However, when using psychological constructs, lower values of Cronbach's $\alpha$ are expected due to the diversity of the constructs being measured [9].

\section{Correlations between patient safety culture composites}

Table 3 shows correlations between the 12 patient safety culture composites, which were found to be significantly correlated. Within the composite on 'Frequency of events reported', the strongest correlation was observed for 'Feedback and communication about error' (Pearson's $r=0.41$ ), while the weakest correlation was for that on 'Staffing' (Pearson's $r=0.17$ ) and 'Non-punitive response to error' (Pearson's $r=0.17$ ).

As for the composite on overall perception of patient safety, the strongest correlation was for 'Management expectations and actions promoting safety' (Pearson's $r=0.63$ ), and the weakest was for 'Communication openness' (Pearson's $r=0.47$ ).

\section{Generalized estimating equations for the patient safety composite scores and respondent characteristics against the patient safety grade and the number of events reported}

As shown in Table 4, five safety composites were found to be significantly associated with patient safety grade. Patient safety grades has 2.3 higher odds (95\% CI: 1.5, 3.4) for every unit increase in 'Hospital handoffs \&

Table 3 Correlations between patient safety culture composites ${ }^{*}$

\begin{tabular}{|c|c|c|c|c|}
\hline & \multicolumn{2}{|c|}{ Frequency of events reported } & \multicolumn{2}{|c|}{ Overall perception of safety } \\
\hline & Pearson's r & $P$ & Pearson's r & $\mathrm{P}$ \\
\hline Supervisor/Manager expectations and actions promoting safety & 0.27 & $<0.001$ & 0.63 & $<0.001$ \\
\hline Organizational learning-continuous improvement & 0.26 & $<0.001$ & 0.61 & $<0.001$ \\
\hline Teamwork within hospital units & 0.22 & $<0.001$ & 0.54 & $<0.001$ \\
\hline Staffing & 0.17 & $<0.001$ & 0.49 & $<0.001$ \\
\hline Hospital management support for patient safety & 0.26 & $<0.001$ & 0.58 & $<0.001$ \\
\hline Hospital handoffs and transitions & 0.27 & $<0.001$ & 0.57 & $<0.001$ \\
\hline Communication openness & 0.33 & $<0.001$ & 0.47 & $<0.001$ \\
\hline Feedback and communication about errors & 0.41 & $<0.001$ & 0.49 & $<0.001$ \\
\hline Non-punitive response to error & 0.17 & $<0.001$ & 0.50 & $<0.001$ \\
\hline Teamwork across hospital units & 0.24 & $<0.001$ & 0.53 & $<0.001$ \\
\hline
\end{tabular}

${ }^{*} N=1562$, correlation is significant at the 0.01 level (2-tailed) 
Table 4 Results of the generalized estimating equations for the patient safety composite scores and respondent characteristics

\begin{tabular}{|c|c|c|c|c|}
\hline & \multicolumn{2}{|c|}{ Patient safety grade } & \multicolumn{2}{|c|}{ Number of events reported } \\
\hline & OR $(95 \% \mathrm{Cl})$ & $\mathrm{P}$ & OR $(95 \% \mathrm{Cl})$ & $\mathrm{P}$ \\
\hline \multicolumn{5}{|l|}{ Patient safety culture composites } \\
\hline $\begin{array}{l}\text { Supervisor/Manager expectations \& actions promoting } \\
\text { patient Safety }\end{array}$ & $1.6(1.1,2.4)$ & 0.02 & $1.3(1.0,1.7)$ & 0.07 \\
\hline Organizational learning-continuous improvement & $2.1(1.3,3.2)$ & 0.001 & $0.9(0.7,1.2)$ & 0.51 \\
\hline Teamwork within units & $1.2(0.9,1.7)$ & 0.22 & $0.9(0.7,1.1)$ & 0.34 \\
\hline Communication openness & $1.4(1.0,2.0)$ & 0.03 & $0.9(0.8,1.1)$ & 0.50 \\
\hline Feedback and communications about error & $1.3(0.9,1.8)$ & 0.09 & $1.0(0.8,1.3)$ & 0.95 \\
\hline Non-punitive response to error & $1.1(0.8,1.4)$ & 0.34 & $1.1(0.9,1.3)$ & 0.23 \\
\hline Staffing & $1.2(0.9,1.6)$ & 0.27 & $0.8(0.7,0.9)$ & 0.044 \\
\hline Hospital management support for patient safety & $2.0(1.3,3.1)$ & 0.001 & $1.4(1.0,1.8)$ & 0.024 \\
\hline Hospital handoffs \& transitions & $2.3(1.5,3.4)$ & $<0.001$ & $0.7(0.5,0.9)$ & 0.006 \\
\hline Teamwork across hospital units & $0.8(0.5,1.3)$ & 0.42 & $0.9(0.7,1.2)$ & 0.37 \\
\hline \multicolumn{5}{|l|}{ Gender } \\
\hline Male & $1.1(0.8,1.7)$ & 0.55 & $1.3(1.0,1.7)$ & 0.088 \\
\hline Female & 1 & & 1 & \\
\hline \multicolumn{5}{|l|}{ Job category } \\
\hline Doctor & $1.8(0.6,5.2)$ & 0.29 & $3.1(1.2,8.1)$ & 0.019 \\
\hline Nurse & $1.0(0.3,2.8)$ & 0.96 & $3.1(1.2,7.9)$ & 0.020 \\
\hline Technician & $2.1(0.8,5.8)$ & 0.16 & $1.5(0.6,3.8)$ & 0.42 \\
\hline Administrator & 1 & & 1 & \\
\hline \multicolumn{5}{|l|}{ Work unit } \\
\hline Medical & $1.1(0.6,2.1)$ & 0.77 & $1.2(0.8,1.8)$ & 0.45 \\
\hline Surgical & $1.4(0.8,2.5)$ & 0.26 & $0.8(0.5,1.1)$ & 0.18 \\
\hline ICU, operating room, anesthesiology & $1.9(0.9,4.1)$ & 0.11 & $0.4(0.3,0.7)$ & 0.002 \\
\hline Administration & $2.2(0.8,6.0)$ & 0.13 & $0.8(0.3,2.0)$ & 0.64 \\
\hline Diagnostic & 1 & & 1 & \\
\hline \multicolumn{5}{|l|}{ Clinical department or not } \\
\hline Yes & $0.8(0.5,1.3)$ & 0.33 & $0.9(0.6,1.4)$ & 0.76 \\
\hline No & 1 & & 1 & \\
\hline \multicolumn{5}{|l|}{ Experience in current hospital (years) } \\
\hline Less than 1 & $0.6(0.2,1.5)$ & 0.26 & $0.4(0.2,0.7)$ & 0.002 \\
\hline 1 to 5 & $0.6(0.3,1.1)$ & 0.11 & $0.9(0.6,1.3)$ & 0.55 \\
\hline 6 to 10 & $0.5(0.3,0.9)$ & 0.022 & $0.9(0.6,1.3)$ & 0.51 \\
\hline 11 to 15 & $0.4(0.2,0.8)$ & 0.008 & $0.9(0.6,1.4)$ & 0.67 \\
\hline 16 to 20 & $0.6(0.3,1.2)$ & 0.12 & $0.7(0.5,1.2)$ & 0.21 \\
\hline 21 years or more & 1 & & 1 & \\
\hline \multicolumn{5}{|l|}{ Job involves direct contact with patients } \\
\hline Yes & $0.8(0.5,1.2)$ & 0.26 & $1.3(1.0,1.9)$ & 0.055 \\
\hline No & 1 & & 1 & \\
\hline
\end{tabular}

transitions', 2.1 (95\% CI: 1.3, 3.2), for every unit increase in 'Organizational learning-continuous improvement', 2.0 (95\% CI: 1.3, 3.1), for every unit increase in 'Hospital management support for patient safety', 1.6 (95\% CI: 1.1,
2.4), for every unit increase in 'Supervisor/Manager expectations' \& 'Actions promoting patient safety', 1.4 (95\% CI: 1.0, 2.0), and for every unit increase in 'Communication openness'. 
An increase in 'Hospital handoffs \& transitions', 'Hospital management support for patient safety', and 'Staffing' led to higher odds of reporting a higher number of events.

OLS was tested as sensitivity analyses. Findings were similar.

\section{Comparison of the 12 composite means with international and regional findings}

Data in Fig. 1 show the variation in differences of patient safety culture composite means in the United States [10], Beijing [11], and other countries or regions [12-16]. Taking into account the differences between health policy and economic conditions, we focus our discussion on another survey in Beijing [11] similar to our hospital's overall situation. Compared to average scores of hospitals in Beijing, the scores of PUCH were significantly higher in all 12 composites. Since China is a developing country, we also concerned about the differences with developed countries such as the United States [10]. Compared to the United States, the sampled hospital scores were significantly lower on 'Communication openness' and 'Frequency of events reported', and other scores were significantly higher except 'Staffing'.

\section{Comparison of the 12 composites data of 2018 with the data of 2019}

The HSOPSC was conducted in April 2019, with a total of 1562 of the 1972 questionnaires was returned for a

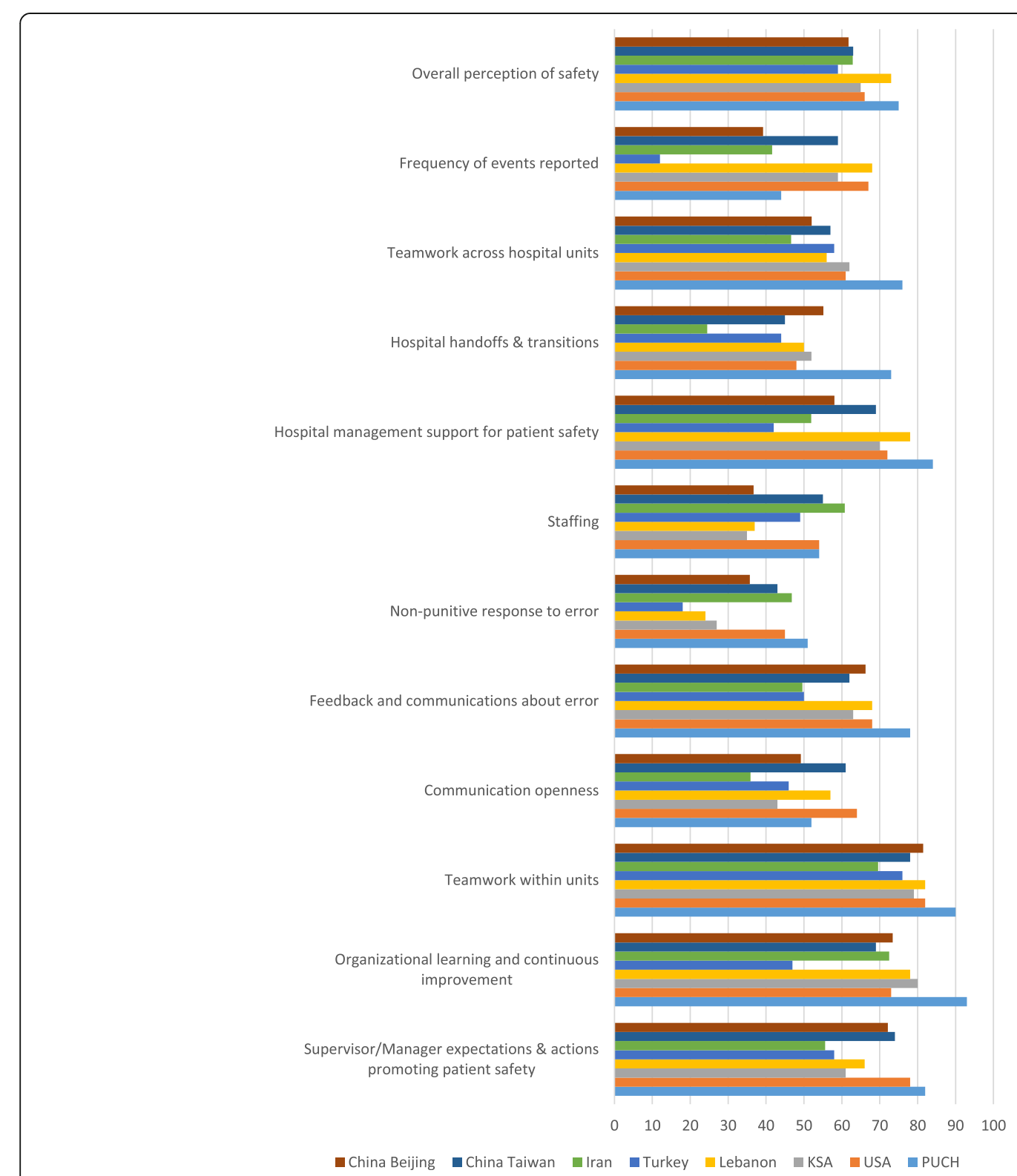

Fig. 1 Composite-level average per cent positive response for PUCH compared to that of other countries and regions 
response rate of $79.2 \%$. Surprisingly, all 12 dimensions increased in the safety culture conducted in 2019 (Table 5), and 4 dimensions remain in the lowest positive response group, include 'Frequency of events reported' (47.9, 43.9\% in 2018), 'Non-punitive response to error' (54.3, 51.1\% in 2018), 'Communication openness' (55.3, 52.2\% in 2018), and 'Staffing' (55.9, 53.7\% in 2018). It indicates that results of the baseline survey in 2018 might be helpful in designing interventions aimed at improving the safety culture in this organization.

\section{Discussion}

'Frequency of events reported' (43.9\%), 'Non-punitive response to error' (51.1\%), 'Communication openness' (52.2\%), and 'Staffing' (53.7\%) had the lowest scores. Of the two outcome composites, 'Frequency of events reported' and 'Overall perception of patient safety', the strongest correlation was for 'Feedback and communication about error' (Pearson's $r=0.41$ ) and 'Management expectations and actions promoting safety' (Pearson's $r=0.63$ ). Five safety composites were found to be significantly associated with patient safety grade.

\section{Comparison of the 12 composites means with international and regional findings}

Compared to Beijing, the sampled hospital scores were significantly higher in all 12 composites, suggesting the sampled hospital has a relatively positive safety culture compared with the average safety culture level in hospitals in Beijing. Compared to the United States, the sampled hospital scores were significantly lower on 'Communication openness' and 'Frequency of events reported', which is consistent with the hierarchy of clustered findings. PUCH performance is weak in the dimensions 'communication openness' and 'frequency of events reported', indicating a need for management changes to improve performance. There is no significant difference in 'Staffing' between the sampled hospital and the United States average, which is clustered in the lowest group.

\section{Policy implications for hospital management}

A culture of safety is fundamental when seeking improvement of quality in healthcare delivery. It is defined as shared values, attitudes and perceptions of safety within an organization that have the goal of minimizing risk of patient harm. It includes the following components: (1) recognizing that high-risk settings are more error prone, (2) nurturing a blame-free environment, (3) management allocating resources for safety concerns, and (4) collaboration among professional disciplines to seek solutions. Organizations with a positive safety culture are characterized by mutual trust, open communication, shared perceptions about safety issues, and confidence about the effectiveness of preventive measures [3].

The findings of this study suggest that hospital leadership must be concerned that interventions focus on feedback and communication about error, as well as communication openness. As stated by Sammer et al. [17], "a common theme running through the literature suggests the role of senior leadership is a key element to designing, fostering, and nurturing a culture of safety." Building safety cultures and improving the quality and safety of care will not occur in environments where staff do not feel supported to communicate and report errors or near miss incidents.

Repeated measurement over several years is needed to track performance evolution in these dimensions. Greater attention to performance in the individual dimensions must be paid by hospital management in order to evaluate organizational readiness to deploy patient safety strategies. In the future, the hospital management

Table 5 Distribution of positive responses and scores for survey composites and items in 2019 compared with 2018

\begin{tabular}{|c|c|c|c|}
\hline Composites and survey items & $\begin{array}{l}\text { Average positive } \\
\text { response of } 2019(\%)\end{array}$ & $\begin{array}{l}\text { Average positive } \\
\text { response of } 2018(\%)\end{array}$ & US Average (\%) \\
\hline Overall perception of safety & 78.6 & 74.6 & 66 \\
\hline Supervisor/Manager expectations \& actions promoting patient safety & 84.0 & 81.6 & 78 \\
\hline Organizational learning and continuous improvement & 94.2 & 92.9 & 73 \\
\hline Teamwork within units & 90.3 & 89.7 & 82 \\
\hline Non-punitive response to error & 54.3 & 51.1 & 45 \\
\hline Staffing & 55.9 & 53.7 & 54 \\
\hline Hospital management support for patient safety & 86.3 & 83.7 & 72 \\
\hline Teamwork across hospital units & 77.9 & 76.2 & 61 \\
\hline Hospital handoffs \& transitions & 76.7 & 73.1 & 48 \\
\hline Communication openness & 55.3 & 52.2 & 64 \\
\hline Feedback and communications about error & 79.9 & 77.6 & 68 \\
\hline Frequency of events reported & 47.9 & 43.9 & 67 \\
\hline
\end{tabular}


should adjust the patient safety strategy based on the results of these two surveys to improve the management and consciousness level to construct a good safety culture in the hospital.

\section{Limitations}

Our study has some limitations. We only studied the safety culture of our own hospital. We are an oncology hospital and the conclusions of our study may not be applicable to other tertiary hospitals. However, our study may be helpful for hospitals willing to assess and improve their patient safety culture in China.

\section{Conclusion}

Patient safety is considered to be crucial for healthcare organizations that want to improve overall performance and quality of services. Assessment of patient safety culture in these healthcare organizations is necessary, and more importantly, make changes based on the results of such assessments. As for our surveys, this hospital has potential for improvement in feedback and communications about error and communication openness. A modified approach and attention are needed to context when designing interventions aimed at improving the safety culture in this organization.

\section{Abbreviations}

AHRQ: Agency for Healthcare Research and Quality; HSOPSC: Hospital Survey on Patient Safety Culture; PUCH: Peking University Cancer Hospital

\section{Acknowledgements}

The authors gratefully acknowledge the manuscript review by Kurt Darr, Professor Emeritus, The George Washington University, Washington, D.C.

\section{Author's contribution}

Z.X.Y and J.J.F participated in the conception and design of the study, data analysis, and interpretation and drafted the manuscript. Y.Q.S., C.D., D.S., L.Y.W and J.C. contributed to interpretation of findings and preparing, reading, revising, and approving the manuscript. All authors have read and approved the manuscript, and ensure that this is the case.

\section{Funding}

This work was supported by Beijing Municipal Administration of Hospitals Incubating Program, Code: PG2018016. The funding bodies had no direct role the design of the study, collection, analysis, and interpretation of data, or in writing the manuscript.

\section{Availability of data and materials}

The datasets used and/or analysed during the current study are available from the corresponding author on reasonable request.

\section{Ethics approval and consent to participate}

This study was approved by Beijing Cancer Hospital Institutional Review Board (2017MS01). Consent to participate was waivered by Beijing Cancer Hospital Institutional Review Board because this study is an anonymous survey conducted in the form of a web survey questionnaire, and the content information is kept confidential.

\section{Consent for publication}

Not applicable.

\section{Author details}

'Key Laboratory of Carcinogenesis and Translational Research (Ministry of Education/Beijing), Peking University Cancer Hospital and Institute, Beijing 100142, China. ${ }^{2}$ Australian Council Healthcare Standards, Ultimo, Australia.

${ }^{3}$ Professor and Senior Associate Dean for Academic and Faculty Affairs, School of Health Professions, University of Alabama at Birmingham, Birmingham, USA. ${ }^{4}$ Department of Medicine, Yong Loo Lin School of Medicine, National University of Singapore, Singapore, Singapore.

${ }^{5}$ Department of Health Services Administration, School of Public Health, University of Maryland, College Park, MD, USA.

Received: 7 October 2018 Accepted: 15 December 2019

Published online: 28 December 2019

\section{References}

1. Leonard M. The essential guide for patient safety officers. edition S, editor. 160 p; 2013

2. U.S. Department of Health \& Human Services. Agency for healthcare research and quality. November 2017. Available at: https://www.ahrq.gov/ cpi/about/index.html. Accessed 28 July 2018.

3. Nieva VF, Sorra J. Safety culture assessment: a tool for improving patient safety in healthcare organizations. Qual Saf Health Care. 2003;12(Suppl 2):ii17-23.

4. Wang M, Tao H. How does patient safety culture in the surgical departments compare to the rest of the county hospitals in Xiaogan City of China? Int J Environ Res Public Health. 2017;14:10.

5. Zhu J, Li L, Li Y, Shi M, Lu H, Garnick DW, et al. What constitutes patient safety culture in Chinese hospitals? Int J Qual Health Care. 2012;24(3):250-7.

6. Nie Y, Mao X, Cui H, He S, Li J, Zhang M. Hospital survey on patient safety culture in China. BMC Health Serv Res. 2013;13:228.

7. Sorra JSNV. Hospital survey on patient safety culture. Publication no.04-0041. ed. Rockville: Agency for Healthcare Research and Quality: AHRQ; 2004.

8. Bowling A. Research methods in health. Buckingham: Open University Press; 1997.

9. Field A. Discovering statistics using IBM SPSS statistics. Los Angeles: Sage; 2013.

10. Sorra JFT, Dyer N, Nelson D, et al. Hospital Survey on Patient Safety Culture: 2009 Comparative Database Report, AHRQ. Rockville: Agency for Healthcare Research andQuality; 2009. Available at: http://psnet.ahrq.gov/resource. aspx?resourcelD=10206. Accessed 26 July 2018.

11. S L. Hospital Survey on Patient Safety Culture in Tertiary General Hospitals in Beijing. Peking Union Medical College. 2014.

12. Chen IC, Li HH. Measuring patient safety culture in Taiwan using the Hospital Survey on Patient Safety Culture (HSOPSC). BMC Health Serv Res. 2010;10:152.

13. El-Jardali F, Sheikh F, Garcia NA, Jamal D, Abdo A. Patient safety culture in a large teaching hospital in Riyadh: baseline assessment, comparative analysis and opportunities for improvement. BMC Health Serv Res. 2014;14:122.

14. El-Jardali F, Jaafar M, Dimassi H, Jamal D, Hamdan R. The current state of patient safety culture in Lebanese hospitals: a study at baseline. Int J Qual Health Care. 2010;22(5):386-95.

15. Bodur S, Filiz E. A survey on patient safety culture in primary healthcare services in Turkey. Int J Qual Health Care. 2009;21(5):348-55.

16. Asefzadeh $\mathrm{S}$, Kalhor R, Tir M. Patient safety culture and job stress among nurses in Mazandaran, Iran. Electron Physician. 2017;9(12):6010-6.

17. Sammer CE, Lykens K, Singh KP, Mains DA, Lackan NA. What is patient safety culture? A review of the literature. J Nurs Scholarsh. 2010;42(2):156-65.

\section{Publisher's Note}

Springer Nature remains neutral with regard to jurisdictional claims in published maps and institutional affiliations.

\section{Competing interests}

The authors declare that they have no competing interests. 